\title{
PESQUISA
}

\section{Controle de escurecimento enzimático em chips de yacon}

REBELO, Andrey Martinez ${ }^{\star}$; CASALI, Elaine Zeni" ${ }^{\star \star}$; BERTOLDI Fabiano Cleber ${ }^{\star \star \star}$

\begin{abstract}
Resumo
Preservar as características organolépticas de alimentos minimamente processados tem sido um desafio. Com vistas à produção de chips de yacon de qualidade comercial, testou-se descascamento de túberas por escarificação ou por choque térmico e descascamento químico. Empregou-se suco de limão-cravo (Citrus limonium), ácido ascórbico e cítrico mimetizando a concentração destes no suco de limão, como antioxidante contra o escurecimento enzimático oxidativo dos chips. O fatiamento foi com fatiador elétrico e a secagem por meio de ar forçado a $45-50{ }^{\circ} \mathrm{C}$. As fatias originadas do beneficiado por choque térmico, descascamento químico e imersão por 10 minutos em solução contendo suco de limãocravo forneceram chips de melhor aspecto visual, por não apresentar escurecimento durante todo o processo. O suco de limão-cravo pode ser empregado como antioxidante na preservação das características visuais de chips de túberas de yacon tratadas por choque térmico e descascamento químico, graças ao ácido cítrico nele contido.

Palavras-chave: Ácido cítrico. Antioxidação. Escurecimento enzimático. Polymnia sonchifolia.
\end{abstract}

\section{Control of enzymatic browning in chips yacon}

\begin{abstract}
Preserve the organoleptic characteristics of minimally processed foods has been a challenge. Aiming at production of yacon chips commercial quality, we tested stripping of roots by scarification or thermal shock and chemical peeling. We applied the lemon juice, cloves (Citrus Limonium), ascorbic acid and citric acid concentrations mimicking those in the lemon juice as an antioxidant against oxidative enzymatic browning of the chips. The slicing was with electric slicer and drying by forced air at 45-500C. Slices received originated from thermal shock, chemical peeling and soaking for 10 minutes in a solution containing lemon juice cloves chips provided the best visual aspect by not showing browning during the entire process. Lemon juice cloves can be used as an antioxidant in preserving qualities of visual chips yacon tubers treated by heat shock and chemical peeling, thanks to the citric acid contained therein.
\end{abstract}

Keywords: Citric acid. Oxidation. Enzymatic browning. Polymnia sonchifolia

\footnotetext{
- Mestre em Farmácia; pesquisador da Empresa de Pesquisa Agropecuária e Extensão Rural de Santa Catarina (Epagri), Estação Experimental de Itajaí, Rod. Antônio Heil, Km 6, Cx.P. 277, 88301-970, Itajaí, SC; andrey@epagri.sc.gov.br

*^ Tecnóloga de Alimentos; extensionista da Empresa de Pesquisa Agropecuária e Extensão Rural de Santa Catarina (Epagri), Gerência Regional de São Miguel do Oeste; Rua 7 de Setembro, 2034, Cx.P. 281, 89.900-000, São Miguel do Oeste, SC; casali@epagri.sc.gov.br

** Doutor em Ciência dos Alimentos; pesquisador da Empresa de Pesquisa Agropecuária e Extensão Rural de Santa Catarina (Epagri), Estação Experimental de Itajaí, Rod. Antônio Heil, Km 6, Cx.P. 277, 88301-970, Itajaí, SC; fabianobertoldi@epagri.sc.gov.br
} 


\section{INTRODUÇÃO}

O yacon (Polymnia Sonchifolia Poepp.\& Endl) é uma planta herbácea, perene, da família botânica Asteraceae, originária dos Andes (LACHMAN; FERNANDEZ; ORSÁK, 2003). Pode ser encontrado desde a Venezuela até o norte da Argentina, em altitudes de 1.000 a 3.200 m. Na Colômbia, Equador e Peru é cultivada em altitudes de 900 a 3.400 m (CASTILHO; NIETO, 1990). Produz tubérculos subterrâneos suculentos, ricos em frutanos e fibras não digeríveis (CARVALHO et al., 2004). Pelo seu conteúdo de frutanos, as túberas de yacon são indicadas na nutracêutica (GIBSON; ROBERFROID, 1995). Suas folhas e túberas, ricas em inulina, são indicadas no auxílio do tratamento de diabetes e de distúrbios do colesterol (HIDAKA; HIRAYAMA, 1991). A inulina, ainda, é capaz de estimular o crescimento de bactérias não virulentas ao ser humano ou benéficas, como as bifidobactérias e lactobacilos, ao mesmo tempo que inibe as bactérias patogênicas Clostridium sp. e Escherichia coli (GIBSON, 1998). Além disso, o consumo de inulina incrementa a absorção de cálcio e magnésio pelo intestino grosso em até 65\% (TANNOCK, 1999).

As túberas, quando oferecidas in natura, tendem à oxidação e ao apodrecimento aproximadamente dois a três dias após a colheita (CABELLO, 2005). Para prolongar a conservação do produto recomendase transformá-lo em fatias desidratadas, que podem ser conservadas por até um ano, quando guardadas em recipientes herméticos (MICHELS, 2005). No entanto, na produção de fatias desidratadas (chips) ocorre escurecimento em razão da oxidação enzimática, resultando em chips de coloração escura, ou seja, com alterações das características visuais indesejáveis que, segundo Ramalho e Jorge (2006), podem ser reduzidas pelo emprego de antioxidantes. Segundo Botrel e Carvalho (1993), o escurecimento oxidativo é catalisado por enzimas do grupo das polifenoloxidases (PPO) e resulta da oxidação de fenóis e até de eventual polimerização não enzimática de quinonas formadas em taninos e melaninas. De acordo com Cabello (2005), a oxidação ocorre com a presença de oxigênio livre, escurecendo rapidamente a superfície recém-cortada dos tubérculos de yacon, prejudicando a aparência do produto e de seus subprodutos. As enzimas, o substrato e o oxigênio são responsáveis pela oxidação. A interferência na ação de um destes impede a ocorrência da reação oxidativa. $O$ controle do escurecimento enzimático pode ser feito por meio de aquecimento do produto, que inativa polifenoloxidase e peroxidase, responsáveis pela reação de escurecimento (BOTREL; CARVALHO, 1993).

Considerando-se que processos oxidativos são controlados por antioxidantes, tem-se por hipótese que o suco de limão pode ser empregado contra o escurecimento oxidativo de túberas de yacon beneficiadas.

O objetivo deste trabalho foi avaliar o emprego do suco de limão, associado a diferentes formas de beneficiamento de túberas de yacon, contra o seu escurecimento enzimático durante o processamento de chips.

Evidência, Joaçaba v. 8 n. 1-2, p. 7-16, janeiro/dezembro 2008 


\section{MATERIAIS E MÉTODO}

O trabalho realizado com túberas de yacon (Polymnia Sonchifolia Poepp.\& Endl) - Asteraceae, foi conduzido em laboratórios da Estação Experimental de Itajaí/Epagri, em Itajaí, SC. Os tubérculos, produzidos em Apiúna, SC (800 m de altitude, longitude 49²2' 23” O e latitude $27^{\circ} 03^{\prime} 00^{\prime \prime}$ S, clima tipo $\mathrm{Cfb}$, conforme a classificação de Köeppen), foram colhidos no mês de março de 2004, por ocasião do final do ciclo de cultivo.

As túberas de yacon, sadias, sem coloração arroxeada ou preta, foram lavadas em água corrente logo após a colheita. O beneficiamento ocorreu sete dias após armazenamento à sombra, sob temperatura ambiente, em local seco e naturalmente ventilado.

\subsection{DESCASCAMENTO E FATIAMENTO DAS TÚBERAS}

Dois processos de descascamento das túberas foram realizados, sendo um por escarificação e outro por choque térmico seguido de descascamento químico. No processo por escarificação, utilizaram-se dois quilos de túberas cortadas em pedaços, de forma a se obter formatos com largura e comprimento semelhantes. Após, foram postos em um escarificador de placa abrasiva (descascador de batatas) até total retirada das cascas presentes. Já o processo por choque térmico e descascamento químico, utilizaram-se dois quilos de túberas colocadas inteiras, em três litros de água fervente e ainda ao fogo. Após retorno da fervura adicionaram-se $100 \mathrm{~g}$ de cloreto de amônio. Depois de dois minutos de reação, as túberas foram retiradas da água fervente para serem rapidamente lavadas em água corrente, à temperatura ambiente e, ao mesmo tempo, descascadas por fricção, usando-se para isso uma espátula metálica. Cada túbera descascada foi imediatamente imersa em água contendo gelo para sofrer choque térmico em temperatura de $5^{\circ} \mathrm{C}( \pm 2)$.

Após o descascamento em ambos os procedimentos, o produto foi fatiado com $4 \mathrm{~mm}$ de espessura em fatiador elétrico com lâminas de aço inoxidáveis.

\subsection{TRATAMENTOS DE CONSERVAÇÃO E INIBIÇÃO DA OXIDAÇÃO DAS FATIAS}

Todos os tratamentos $(\mathrm{T})$ foram realizados em triplicata. As fatias foram imersas por 10 minutos em dois litros de água destilada, ou de solução, a saber: (T1) água destilada; (T2) água destilada e 50 $\mathrm{mL}$ de suco puro, fresco e natural de limão-cravo (Citrus limonea); (T3) água destilada e 7,03 g de ácido cítrico; (T4) água destilada e $24 \mathrm{mg}$ de ácido ascórbico; (T5) água destilada, 7,03g de ácido cítrico e 24 mg de ácido ascórbico.

Evidência, Joaçaba v. 8 n. 1-2, p. 7-16, janeiro/dezembro 2008 
Andrey Martinez Rebelo, Elaine Zeni Casali, Fabiano Cleber Bertoldi

As quantidades de ácido cítrico e de ácido ascórbico empregadas nos tratamentos equivaleram às quantidades presentes em $50 \mathrm{~mL}$ de suco de limão-cravo, determinadas por acidez titulável - método de iodo de acordo com método do Instituto Adolfo Lutz (1985).

\subsection{DESIDRATAÇÃO E AVALIAÇÃO DAS FATIAS}

As fatias de túberas de yacon foram distribuídas uniformemente, em até três camadas, em bandejas teladas e forradas com folhas duplas de papel filtro para desidratação em secador com fluxo de ar contínuo sob temperatura de 45 e $50^{\circ} \mathrm{C}$, por 24 horas.

As fatias depois de secas (chips) foram espalhadas uniformemente, por tratamento, em bandejas. Determinou-se a eficiência dos tratamentos empregados, por meio de percentagem de chips escurecidos.

\section{RESULTADO E DISCUSSÃO}

Durante o processo de descascamento das túberas por escarificação com placas abrasivas, houve escurecimento da superfície do produto e não ocorreu descascamento completo (Fotografia 1).

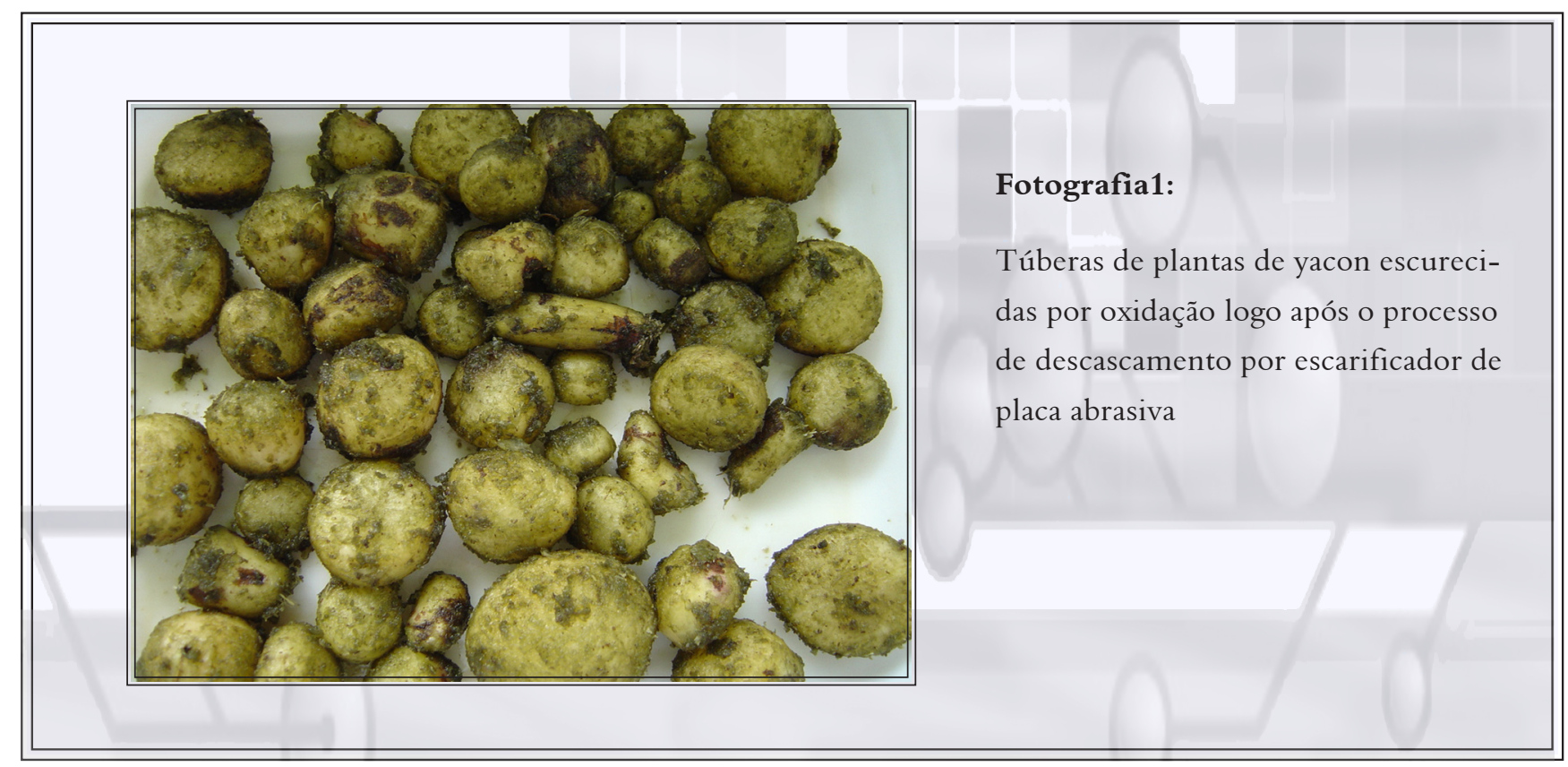

Evidência, Joaçaba v. 8 n. 1-2, p. 7-16, janeiro/dezembro 2008 
O processo de oxidação destas túberas se intensificou durante o seu fatiamento e prosseguiu mesmo durante a imersão nas soluções de cada tratamento (Fotografia 2). Os chips formados a partir das túberas descascadas por escarificador de placas abrasivas apresentaram escurecimento mais intenso após o secamento das fatias (Fotografia 3).

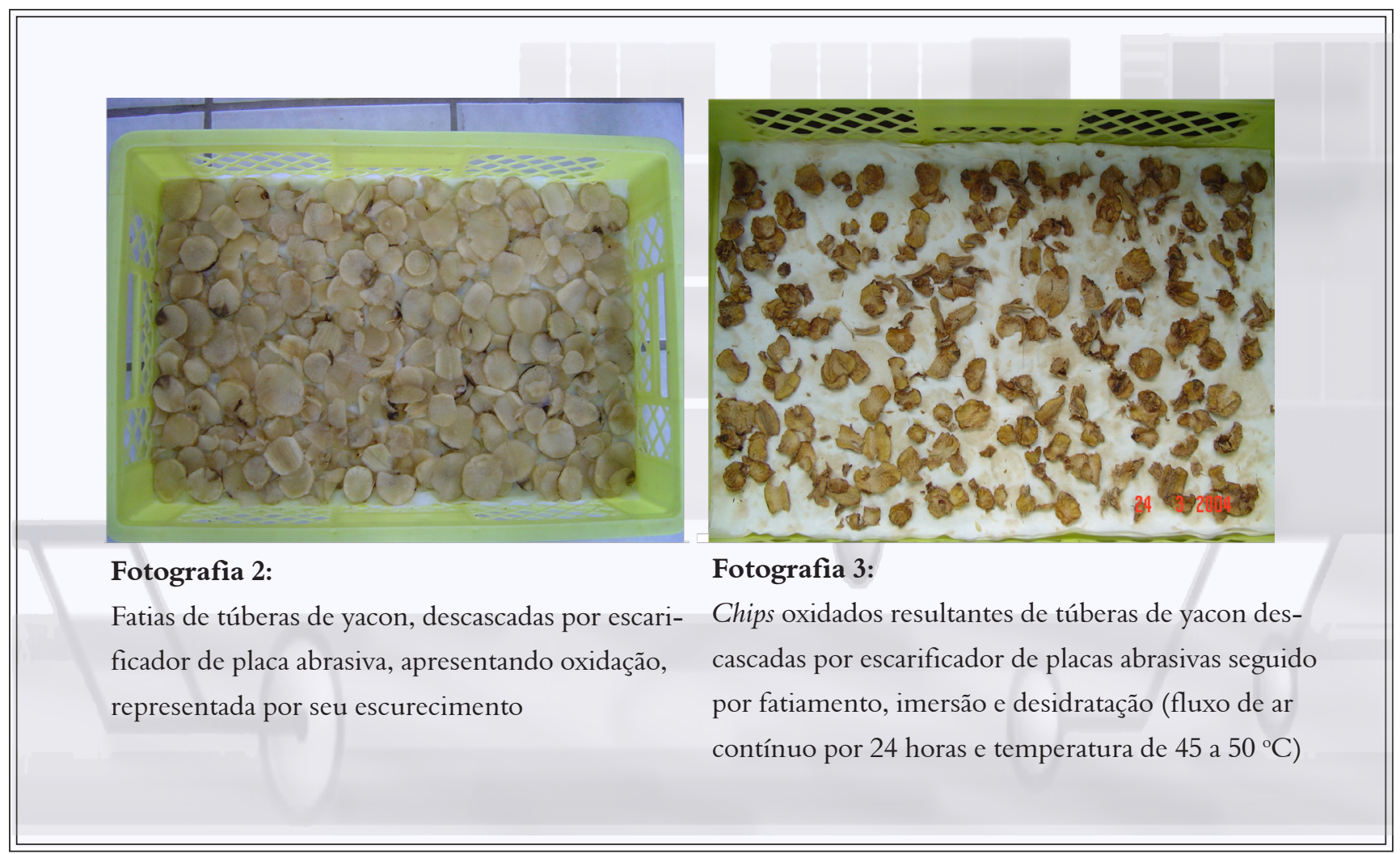

Após descascamento das túberas por choque térmico e descascamento químico, obteve-se material sem escurecimento, praticamente isento de casca e preservação das características visuais (Fotografia 4), depois do descascamento, durante o fatiamento e, ainda, após a imersão nas soluções de cada tratamento (Fotografia 5). 
Andrey Martinez Rebelo, Elaine Zeni Casali, Fabiano Cleber Bertoldi

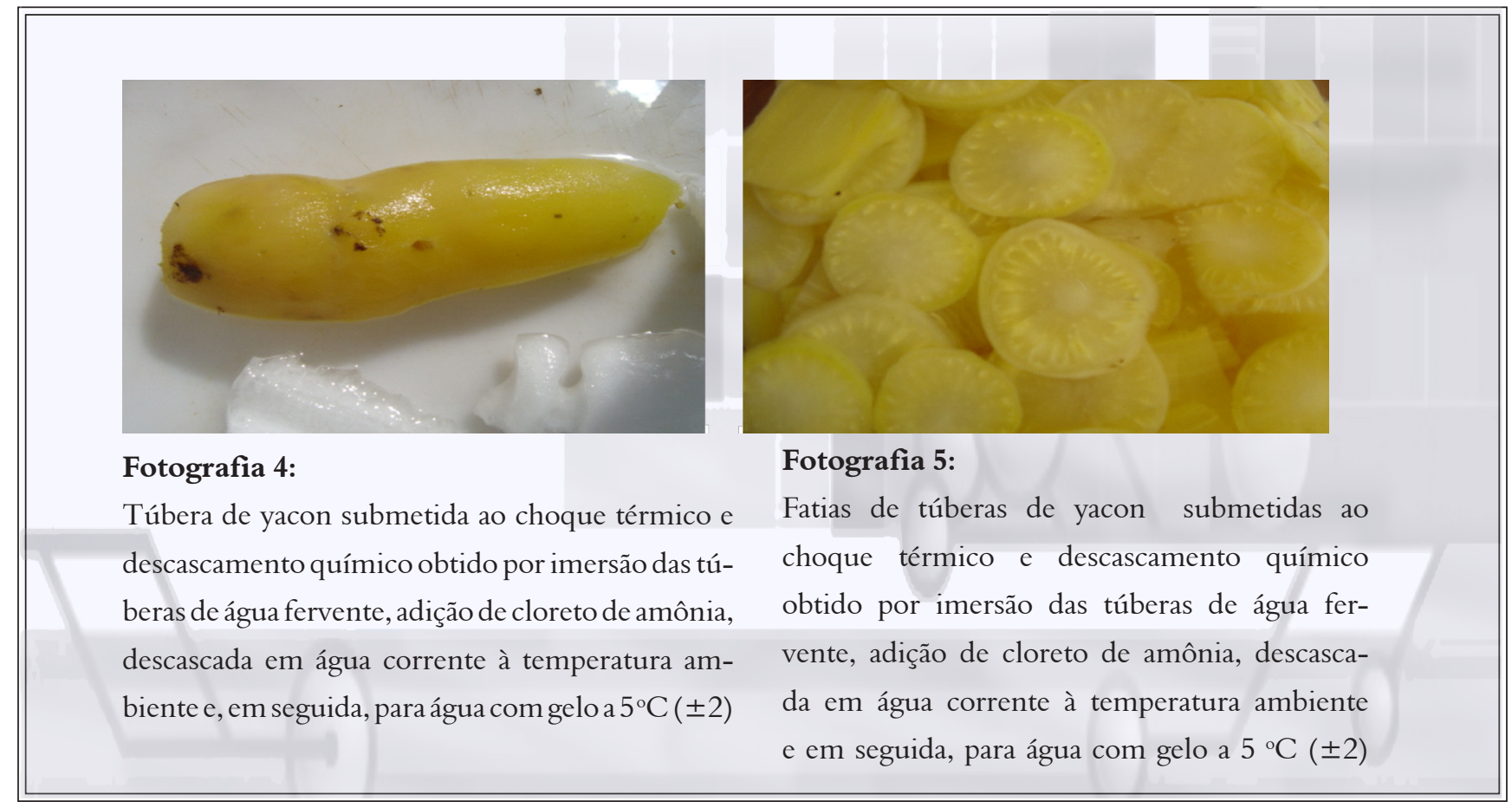

No entanto, após a secagem, as fatias que foram imersas em água destilada (T1) ou em solução de ácido ascórbico (T4) apresentaram manchas verde-azuladas e escurecimento em 95 e $91 \%$ dos chips, respectivamente (Fotografia 6).

As fatias imersas em solução de água destilada e suco de limão (T2); água destilada e ácido cítrico (T3), ou água destilada e ácido cítrico mais ácido ascórbico (T5), apresentaram pouca ou nenhuma alteração em suas características visuais após a secagem. Apenas 3,4 e 4\% dos chips escureceram para cada tratamento descrito, respectivamente (Fotografia 7).

A oxidação observada nas túberas descascadas por escarificação ocorreu, provavelmente, pelo maior tempo de exposição ao oxigênio durante o processo de descascamento (CABELLO, 2005). No processo de descascamento por choque térmico e químico, as túberas ficam imersas durante todo o processo de retirada da casca, o que reduziu a exposição ao oxigênio. Por outro lado, a imersão em água não preservou essas túberas da oxidação, quando novamente expostas ao oxigênio, o que aconteceu com os chips tratados apenas com imersão em água, que escureceram durante o processo de secagem.

Evidência, Joaçaba v. 8 n. 1-2, p. 7-16, janeiro/dezembro 2008 
Controle de escurecimento enzimático em chips de yacon

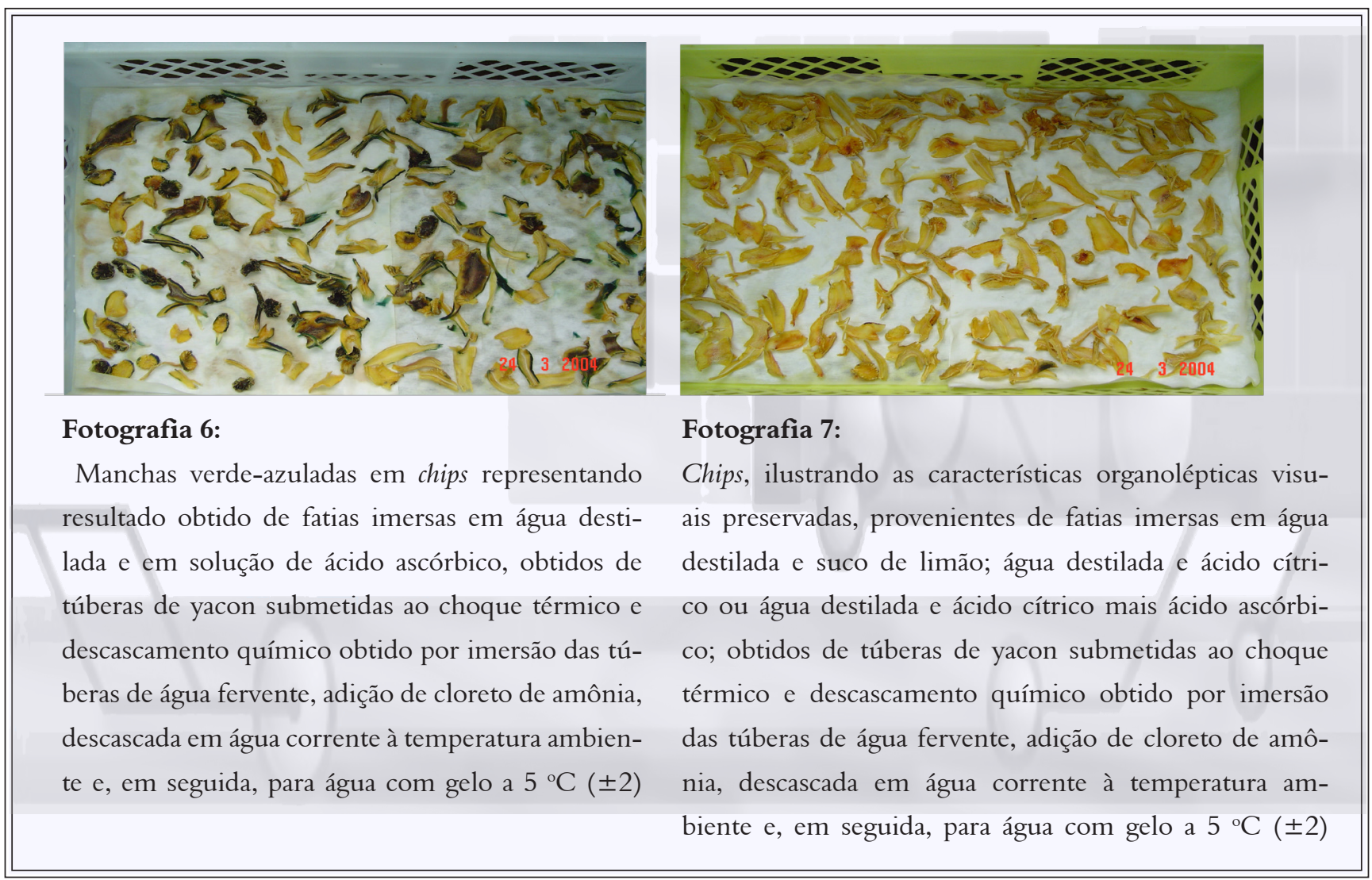

Considerando que, quanto às soluções de imersão, os melhores chips foram obtidos de fatias imersas em solução com ácido cítrico; suco de limão-cravo e ácido cítrico mais ácido ascórbico, deduzse que o resultado é consequência da presença e concentração do ácido cítrico, já que os chips obtidos de fatias imersas em solução de ácido ascórbico não diferiram dos chips testemunha (fatias imersas em água destilada). Segundo Michels (2005), a imersão de fatias de yacon em solução de ácido cítrico, visando à manutenção da cor e das características sensoriais dos tubérculos de yacon minimamente processados e embalados a vácuo é mais eficiente que quando em ácido ascórbico. Entre os principais constituintes do limão há o ácido ascórbico e o ácido cítrico (CARVALHO; BORCHETTA; SILVA, 2006). De acordo com Carvalho e Lima (2002), frutos e hortaliças, minimamente processados, podem ser preservados da oxidação quando imersos em solução de ácido cítrico. $\mathrm{O}$ ácido cítrico também é um agente quelante e é usado sinergicamente com o ácido ascórbico para quelar próoxidantes, causadores de rancidez e para inativar enzimas como a polifenoloxidase, catalisadora de reações de escurecimento (WILEY, 1994; CARVALHO; LIMA, 2002). Neste trabalho, no entanto, o ácido ascórbico, na concentração testada, não conseguiu preservar os chips contra o escurecimento. Segundo Carvalho e Lima (2002), o ácido ascórbico a 1\% não foi capaz de manter a qualidade de kiwi minimamente processado. 


\section{CONCLUSÃO}

Pode-se evitar o escurecimento enzimático oxidativo de chips de túberas de yacon por meio de choque térmico e descascamento das túberas, seguido de imersão das fatias, antes da secagem, em solução contendo ácido cítrico a 0,35\% na proporção de 1:1 (m:v).

Entre o ácido ascórbico e cítrico, nas concentrações presentes no suco de limão-cravo, o segundo é o antioxidante que pode impedir o escurecimento dos chips de túberas de yacon.

O suco de limão-cravo (Citrus limonea) pode ser empregado como antioxidante nos tratamentos que visem a impedir o escurecimento de chips de túberas de yacon após pré-processamento com choque térmico e sal amoníaco.

\section{REFERÊNCIAS}

BOTREL, N.; CARVALHO,V. D. Efeito do peso do fruto no escurecimento interno e qualidade do abacaxi. Atividade de polifenoloxidase, peroxidase e compostos fenólicos. Pesquisa Agropecuária Brasileira, v. 28, n. 6, p. 733-742, 1993.

CABELLO, C. Extração e pré-tratamento químico de frutanos de Yacon, Polymnia sonchifolia. Ciência e Tecnologia de Alimentos, v. 25, n. 2, p. 202-207, 2005.

CARVALHO, A. V.; LIMA, L. C. de O. Qualidade de kiwis minimamente processados e submetidos a tratamento com ácido ascórbico, ácido cítrico e cloreto de cálcio. Pesquisa Agropecuária Brasileira, v. 37, n. 5, 2002.

CARVALHO, L. M. J. de; BORCHETTA, R.; SILVA, E. M. M. Effect of enzymatic hydrolysis on particle size reduction in lemon juice (citrus limon, 1.), cv. tahiti. Brazilian Journal of Food Technology, v. 9, n. 4, p. 277-282, 2006.

CARVALHO, S. et al. Fructanos em raices tuberosas de yacon (Smallathus sonchifolius Poep. \& Endl.) expuestas al sol y almacenadas bajo condiciones ambietales. Agro-Ciência, v. 20, n. 1, p. 1723, 2004.

CASTILHO, R.; NIETO, C. Ecuador increses Andean crop conservation and development work. Diversity, v. 10, p. 13-14, 1990.

Evidência, Joaçaba v. 8 n. 1-2, p. 7-16, janeiro/dezembro 2008 
GIBSON, G. R. Dietary modulation of the human gut microflora using probiotics. Brazilian Journal of Nutrition, v. 80, p. 209-212, 1998.

GIBSON, G. R.; ROBERFROID, M. B. Dietary modulation of the human colonic microbiota: introducing the concept of prebiotic. Journal Nutrition, v. 125, p. 1401-1412, 1995.

HIDAKA, H.; HIRAYAMA, M. Useful characteristics and commercial applications of fructooligosaccharides. Biochemical Society Transactions, v. 19, p. 561-565, 1991.

INSTITUTO ADOLFO LUTZ. Normas analíticas: métodos químicos e físicos para análises de alimentos. 3. ed. São Paulo, 1985. v. 1.

LACHMAN, J.; FERNÁNDEZ, E. C.; M. ORSÁK. Yacon [Smallanthus sonchifolia (Poepp. et Endl.) H. Robinson] chemical composition and use. Plant Soil Environment, v. 49, n. 6, p. 283290, 2003.

MICHELS, I. Aspectos tecnológicos do processamento mínimo de tubérculos de yacon (Polymnia sonchifolia) armazenados em embalagens com atmosfera modificada, 2005. 107 f. Dissertação (Mestrado em Tecnologia de Alimentos)-Universidade Federal do Paraná, Curitiba, 2005.

RAMALHO, V. C; JORGE, N. Antioxidantes utilizados em óleos, gorduras e alimentos gordurosos. Quimica Nova, v. 29, n. 4, p. 755-760, 2006.

TANNOCK, G. W. Identification of lactobacilli and bifidobacteria. England: Tannock GW, 1999. 
